\title{
Effects of the Program: "Salas para la Paz", on the Degree of Human Development of Individuals with Drug Addiction
}

\author{
Héctor González-García1, José Salazar-Cantú², Raymundo Rodríguez-Guajardo², \\ Karla Fernández-Flores ${ }^{2}$, Carlos Ortega-Vázquez ${ }^{2}$ \\ ${ }^{1}$ Political Sciences Department, Universidad Autónoma de Nuevo León, San Nicolás de los Garza, Mexico \\ ${ }^{2}$ Economics Department, Tecnológico de Monterrey, Monterrey, Mexico \\ Email: hector.gonzalezg@uanl.mx, jsalazar@itesm.mx
}

Received 1 March 2015; accepted 24 March 2015; published 27 March 2015

Copyright (C) 2015 by authors and Scientific Research Publishing Inc.

This work is licensed under the Creative Commons Attribution International License (CC BY).

http://creativecommons.org/licenses/by/4.0/

c) (i) Open Access

\section{Abstract}

This study estimates the impact that the program "Salas para la Paz" (Rooms for Peace), implemented by "Promoción de Paz, A.B.P." (Peace Promotion, private association for beneficence), has on different aspects of human development, in individuals with addiction, in Monterrey, México. By testing mean differences and using propensity score matching, group comparisons are made, based on the time the subjects have been in the program. The study is based on information obtained from interviews conducted on the participants, and their families. Results based on the answers of the first group, reveal that the program has little or no effect whatsoever. On the other hand, the answers of the second group lead to mixed results, which tend to confirm that direct participant human development increases starting from the second month of treatment.

\section{Keywords}

Human Development, Addiction, Propensity Score Matching, México

\section{Introduction}

The program "Salas para la Paz" is part of the organization "Promoción de Paz, A.B.P.”, and it started as an alternative to community development, traditional rehabilitation and readaptation programs, for young people that suffer or cause violence, that have any addiction, or those who have committed any crime and are in parole. Promoción de Paz, A.B.P. has its attention centers located in socially vulnerable neighborhoods', and the people in those places are its principal objective group. 
According to [1], the program follows the method of auto-focalization, since it is open to all population, but it is designed in such a way that is acceptance is larger amongst young people suffering from addiction to any substance, or that have suffered from any kind of violence, who lives at socially vulnerable neighborhoods'.

Reference [2] justifies the implementation of the "Salas para la Paz" program as a response to the increase in rates of violence, crime, and addictions, which was lived during the beginning of the $21^{\text {st }}$ century, in the city of Monterrey, Nuevo León, México.

The program puts together a series of classes and workshops on human development, which are focused on developing: Self-esteem, interpersonal skills, and the meaning of life. A constructivist scheme is followed, where the participant understands concepts based on its own knowledge and experience, where team work is fundamental, and is, preferably, achieved through game based therapies.

This study was commissioned by Promoción de Paz, A.B.P., and was based on the conducting of surveys filled by the 333 participants and their families, in 12 rehabilitation centers, located in the metropolitan area of Monterrey, México, during the second semester of 2012.

There are two relevant limitations that come across from the beginning of the research: 1) The objectives and goals that the Salas para la Paz program wishes to achieve are originally scattered and loosely defined, and didn't consider specific indicators during its monitoring, which makes the evaluation process more complex. Because of this, Promoción de Paz, A.B.P., and the team that carried the present study, agreed to evaluate based on a concrete aspect of the personal status of the participant: His or her own human development, conceived by his or her own perception and of his or her family's. 2) Given the wide range of studies that observe human behavior related to violence and addiction, and the bias observed in participants, whom in the larger proportion declared themselves to be addicted to one or many drugs, or alcohol (representing $92.4 \%$ of the whole), the study was focused primarily on the effects of the program over the mentioned group, considering that there would roughly be enough observations to speak about other groups to whom the program is also directed, which are the groups of people that suffer or are involved in problems regarding violent behavior ( $6.6 \%$ of the whole), and the group of paroled criminals, ( $0 \%$ of the whole) ( $1 \%$ of the population involved in the program during the second semester of 2012 didn't associate to any of the three groups to which the program was directed upon).

The main contribution of the study divides between two aspects, the first of them, its originality, since the point where the literature on the subject was reviewed, no studies were found on the evaluation of the impact of programs specialized in the treatment of violence, addictions, and their effects of human development in México.

There are previous evaluations for federal programs such as the Programa de Desarrollo Humano Oportunidades [3] [4], which depended upon the Secretaría de Desarrollo Social (Secretariat of Social Development), where proven benefits amongst its participants are; increase of height, physical wellness, academic achievement, and improvement in home consumption. Still, the impact of the program on human development of the subjects and of those who still are addicted hasn't been evaluated.

Another federal program that deals with the addiction problem, is the Programa Educativo en Materia de Prevención de Adicciones (educational program on prevention), carried by the Secretaría de EducaciónPública (Secretariat of Public Education). This program's impact has not been evaluated, only its performance [5]. As its name indicates, this program is not directed towards people with addiction, but to prevent this behavior amongst people who have not been addicted to substances.

The study's second contribution has to do with the research design itself, which proposes the quasi-experimental group comparison according to [6] and [7], based on their time of stay in the program, and the obtaining of information straight from the participants, as well as from their families or home members. This contribution might lead the path on the implementation of similar designs for other studies that evaluate social programs impact, where the lacking of a control group that is clearly defined or identified, is usually one of the most frequent and important obstacles for formal evaluation. Also, information obtained directly from the subject and his or her family, follows the idea that, by its own personal situation (that is, being addicted), some of the participants in the program might not be an accountable source of information.

The study's methodology considered the comparison between a group of treatment, formed by the participants with 10 or more months in the program, and three other control groups, formed by participants with 4, 2 and 1 month of treatment or less. The statistical tools used for comparison were mean difference t-tests and the use of propensity score matching.

The results of the study show that according to the participant's answers, the program doesn't contribute or 
make a difference in their human development. On the other hand, according to answers given by the families, the program does contribute to a better human development, as long as the subject participates for at least two months in the program, and also, according to the results of the surveys filled by the families of the participants, there are statistically significant effects of the program for those who have been for 10 months in treatment, in comparison to those who participated only for a month, but this effects are minimum and practically imperceptible when a comparison is raised between those who have been 10 months in the program, and those who have been 2 and 4 months, which leads to conclude that the effects could be taking place from the second month, and then becoming noticeable until the tenth month.

The present study didn't evaluate participants who were involved in the program for a period of time superior to 10 months, since there aren't enough observations on these individuals. Still, conducting tests by such groups when exist large enough populations to provide statistical deduction, would allow in following studies to confirm the obtained result on the present one.

The rest of the document is presented in five sections, first the theoretical framework and a description of the program, second, the review of literature, then the results, and finally the conclusions.

\section{Review of Literature}

The present investigation's main objective is to measure the effect that the intervention by the organization Promoción de Paz, A.B.P., through the program: "Salas para la Paz", produces on the levels of human development, on its direct participants. This objective sets out the need to understand the theoretical framework, addictive behaviors, and the interaction between these two subjects.

Given the dimension of these theoretic fields, the ongoing debate on them, as well as having a high proportion of people with addiction amongst the participants in the study, it was decided that this section would be dedicated to a general revision of the existing theoretical and empirical approaches that are referred to more often in the study of human development and addictive behavior.

In the fields of philosophy and economy, Amartya Sen's work is prominent, since it presents arguments that changed in a noticeable way the general approach on human development and the meaning of justice itself. The author emphasizes on the importance of several aspects of a person, such as the elements that constitute its well-being. [8] explains:

The relevant functionings for well-being vary from the most essential, like avoiding mortality and morbidity, being adequately nourished, having motility, etc., to the most complex ones, such as being happy, having self-respect, involving one-self with the community's activities, going out in public without shyness...It is affirmed that these functionings make the self of a person, and that the evaluation of its well-being must be shaped in order to value these constitutive elements. (p. 62)

This approach leads to the development of comprehensive measures for human development by the U.N., which has been a significant contribution to the measurement of the degree of development or under development in different countries.

Sen's concepts, where the foundation for the development of several human well-being indexes, the most notorious of these contemplated in its construction three variables: level of income, education degree, and life expectancy at birth. Despite the usefulness of these concepts to make comparisons between countries, its application on the individual is less practical, since it parts from measurements that might be considered to have been added afterwards and that leave out important ideas of Sen's own philosophy, who calls to observe an individual's development from the so called "capabilities approach", which sees beyond the purely utilitarian approach, mainly focused on happiness or individual pleasure, or the economic, which is focused on income, poverty and resources, he invites to seek out the individual's capabilities for doing things that they have a reason to value. "This approach proposes to concentrate in real living chances, rather than living goods" (p. 264) [9].

From the study of psychology, [10] defines: "Human development refers to the ever changing state of a person's growing towards living plentifully, with a more complete use of its own potential and capabilities” (p. 29). Like [9], this author considers that it is difficult, but not impossible, to evaluate the degree of human development both individually and collectively. Also, she considers that scales that measure personal human development can be made, and in order to do so she offers an instrument that contemplates the inclusion of certain existing elements in test developed for this means in diverse fields related to the study of psychology, such as: Personal orientation's inventory, the “Life’s Purpose Test”, and the Scale of Process in psychotherapy. 
As it will be explained in the methodology section, the main variable of interest in this study, human development, is approached by using the method developed by [10].

As it is stated at the beginning of this section, this investigation approaches human development on a particular group of people, which have as a common-factor addictive behavior, to alcohol, and/or other drugs. In order to understand the impact that a rehabilitation program has on human development in this group, there is also the need to understand the precedents that lead to this kind of states.

In the study of addictive behaviors, [11], quoting Cottler (1931) and Rounsaville, Bryant, Babor, Kranzler and Kadden (1993), defines addiction as a behavior in which an individual has diminished its self-control and it leads to harmful consequences.

Summarizing a review of available literature on theory and evidence on addictions, [12] suggest five factor groups that explain addiction, which are explained in Table 1.

When drawing conclusions for his investigation, [12], in a similar fashion to [13], points out the need for: 1) studying addictions in a more complete way, by detailed analysis through a model that integrates the sum of the factors that cause them; 2) exploring the synergic effects that these diverse mechanisms produce in the development and perpetuation of addiction; and 3) to emphasize the significance of the individual perception of addiction, and approaches for individual treatment. This study contributes directly with the third need mentioned by Bobo, particularly by evaluating a form of treatment.

Reference [14], warn that quantitative and qualitative approaches that have included the study of factors that reflect the context, have generally been limited to describe the process of addiction through time, especially when trying to observe how addiction manifests itself between relationships and daily life. They suggest a more integral understanding of the phenomena through contextual action theory, according to which, intentional action is caused by a series of internal and external factors, that include neurobiology, levels of social and personal security, access to resources, and the existence of abilities.

Contextual action's theory approach used by [14], agrees with Rational Election's theory by [15] who demonstrate how: "even with people with the same level of utility, same amount of wealth, and that pay the same prices, may have different degrees of addiction according to their own experiences” (p. 690).

In the field of sociology, [16] states that the kind of human nature one adopts will depend upon experiences that he have in the social process and that in this fashion, addiction is also socially acquired, which is also estimated by [17] by pointing out that the place where we are defines who we are.

By exploring the relation or relations that theoretically may explain the specific phenomena of human development on an addict, [9] explains that the value that a person gives to its capabilities depends upon the freedom which he or her chose to select them. According to the definition of addiction, this implies self-harm and therefore limits to some degree some capabilities, so we can say that living with addiction also means to experience a lesser human development than what we could reach without addiction.

Reference [18], quoting Kübler-Ross (1969), states that the approach on human development in the study of addictions started in 1930. From this perspective, effects of any treatment will depend upon many factors, but mainly the life stage where the person experienced addiction, same which depends biologically on age, and cognitively on personal aspects, such as: self-confidence, autonomy, initiative, responsibility and interaction.

Table 1. Cause for addiction.

\begin{tabular}{|c|c|}
\hline Group & Cause \\
\hline $\begin{array}{l}\text { Social, historical and cultural } \\
\text { background. }\end{array}$ & First hand experiences, observational learning, cultural context, language and symbols. \\
\hline Predispositions. & $\begin{array}{l}\text { Focusing on the future, consideration for future consequences, } \\
\text { low tolerance for pain, high dependency on reward. }\end{array}$ \\
\hline Past actions/Present choices & $\begin{array}{l}\text { Demand elasticity, temporal discount, information on risks, bias towards naive decision: benefits } \\
\text { today vs. abstention cost today, smart bias: benefits tomorrow vs. abstention cost today. }\end{array}$ \\
\hline Neurobiology & $\begin{array}{l}\text { Brain structure and chemical neurotransmisors, brain structure for pleasure and } \\
\text { reward mechanisms, incentive-sensation of addiction, oppose process: states of } \\
\text { euphoria and depression, both before and after consumption. }\end{array}$ \\
\hline Underlying processes & $\begin{array}{l}\text { Psychological processes outside the individual's introspection, that automatize } \\
\text { addictive behavior. They emerge from outside the individual's conscience. }\end{array}$ \\
\hline
\end{tabular}

Source: Made by authors, based on [12]. 
According to studied material on addictions theories, it is clear that context, as well as the individual, affect the decision to start, continue and remain consuming the addictive substance. It is also clear that the more the time and frequency of consumption, the least the possibility of an autonomous decision to consume and the process escapes the person's control. We can deduct that the process gradually undermines individual freedom and also the individual's capacity, this process is the same which the program Salas para la Paz tries to reverse.

In empirical literature, a group of studies are focused on trying to explain some indicator for drug consumption. At first, addictions like alcohol and tobacco, use of cannabis and cocaine, can be studied via demand for these addictions. From the economical perspective, there are some works that use variants from the same model, in which the individual maximizes a function of utility, subject to its budget restrictions. [19] show that the addiction-phenomena is not inconsistent with the preferences' stability.

Years later, [15] in their theory of rational addiction, say that "rational" means that individuals maximize their utility consistently through time, and a material good is addictive if past increases in consumption affect present consumption. Based on these two articles, [20], states that economics theory emphasizes on addiction to only one substance, but actually there may be addiction to more than one. Using a two-drug model (alcohol and cannabis), [20] raises the problem of maximization of utility (where cannabis and alcohol are included) through life with a budget restriction. From his analysis, an individual starts consuming a drug when the marginal utility for consuming it is bigger than its marginal cost. Given that alcohol consumption has one of the smaller marginal costs, it is probable that the individual that starts consuming does it with alcohol. Nevertheless, once alcohol consumption has started, the marginal utility for consuming both drugs increases, so, given a constant marginal cost for cannabis, it is more probable that the individual starts using cannabis (or cocaine), more costly substances than alcohol. This finding allowed, in the present study, to speak generally on addicts, without making distinctions between those who use alcohol or other drugs.

There are other variables that have been found relevant as for drug consumption. [21] study the relationship between ethnicity, gender, and temper with alcohol consumption. As for the measurements for alcohol consumption, the drinking frequency (on a nine point scale, from "never has consumed", to "consumes every day"), amount typically consumed (on a five point scale, that ranges from "one or two drinks" to "twelve or more drinks"), and recent problems (last year) that started due to consumption. By using MANOVA (multivariate variance analysis) as a method, the authors find that, in general, the three variables have statistically significant effects on at least one of the three measurements of alcoholic behavior. The gender variable affects significantly on the three measurements. Men drink more frequently than women, drink larger amounts, and reported more problems related to drinking.

The review of literature states clear that the addiction phenomenon is very complex and there are multiple determinants for addictive behavior. This represents a formidable challenge to any program that has the objective of helping an addict to eradicate or diminish its addiction and reach a higher status of human development, and to any investigator, to try to evaluate the isolated effect of said program on addictive behavior.

Despite the challenges, there are certain statements that can be obtained from this literature review: a) Even if addiction is considered to be a rational behavior, as it becomes bigger, which is directly related to time and frequency of the use of the addictive substance, the ability to choose dissolves and also the basic components for life, which causes human development to decrease and also the chance to rehabilitate; b) There isn't a single theory that can explain addictive behavior by itself; c) The use of general measurements for human development, is limited as it fails to observe the evolution of effects derived from addictive behaviors, in order to do so effectively, measures that are more understanding of human behavior and consider each individual's circumstances must be applied; d) There is an evident need for empirical research that allows to measure the explanatory importance of the different determinants for addictive behavior and the researchers methods, used on the field, for its own treatment; e) The evaluation of the effects of interventions on human behavior is frequently associated with the use of double difference quasi experimental design. In the revision carried on by the investigation team, no past studies have been found that were carried in such way, with defined groups (control/treatment); f) Of the different theories and methods that have been used for its study, we consider that the use of statistical methods, even if they're not enough, they still are the most used and recommended, and g) The control variables, in studies that try to observe the isolated effect of factors that determine addiction, or also variables that reflect on the efforts to eradicate or lessen it, the latter the present study's case, are commonly; age, gender, condition of occupation, school level and/or socioeconomic status, and family history and components. 


\section{The Attention Model of the "Salas para la Paz" Program in Its Rehabilitation Centers}

The program's main objective is to contribute to the participants' human development. The attention model has two main intervention systems: Herramientas para la Vida (Tools for life) and Arte Urbano (Urban Art). The first of them is balanced on two axis, Human Development and Games Therapy. The program observes internment periods of one, two and three mounts, and some of its participants are recidivist. The fee charged per week of treatment goes between \$500 and \$3000 Mexican pesos (33 to 200 USD, January 2015), depending on the individual's and his or her family's budget. When the person undergoing treatment cannot pay the fee by his or her own resources, he or she receives support through public funding, by either the Secretaría de Salud (Secretariat of Health) or the Instituto de Desarrollo Social (Institute for Social Development), both federal dependencies that provide support programs for the activities of the civil society organizations. The main objective is to attend every applicant in need of support. The individual may pay the established fee, or be subsidized by the mentioned entities, or funding provided by Promoción de Paz, A.B.P., which in the end also come from individuals and private foundation's contributions.

Regarding Human Development, the participant takes a series of workshops and classes that have a constructivist approach and are focused on the following subjects: Self-esteem, communication, the meaning of life, music therapy and conflict solving. Regarding Games Therapy, board games are shared and participants work as a team, in an attempt to stimulate cognitive, concentration and memory skills, making the participants compete with themselves, rather than others.

The second section of the program is Arte Urbano, and it has the objective of generating social integration and communitarian pacification. Musical and artistic activities are used as a way of contributing to the growth of the participant's human development, but also as a way for him or her to interact with others and be in harmony with his community.

Workshops and classes are taken at the rehabilitation centers, located within the neighborhoods where the participants live, facilitators are specialized professionals (psychologists, social workers and criminologists) that work together with program graduates that currently study a career.

\section{Methodology}

Based on the [7] classification, the present study follows a quasi-experimental methodology, which estimates results of a program by comparing between participant groups differentiated according to their time of stay in it. Particularly, the group of participants involved 10 months or more in the program, is treated as the treatment group, and the group of participants with a maximum of 1, 2 and 4 months in the program, is treated as the control group. The study considered the whole population of participants in the program in November 2012, but the formation of these groups followed the need of having balanced groups and enough observations, as well as the need of being able to compare between an initial treatment, from which no significant results could be expected, in this case less than 4 months, and one that already meant a positive outcome expectation, those equal to or more than 10 months.

For testing difference between means T-tests were used (where $\mathrm{H}_{0}: \mu^{1}=\mu^{2}$ ), also the propensity score matching method was used (PSM), which compares each element from the benefactors group with its most similar element from the control group, for the interest variables, in this case level of human development and its 6 components, and the self-reported happiness level, given the control variables. Levels of human development and happiness are compared, from each of the control groups, with the treatment group.

For the obtaining of necessary data for the calculation of the interest variable: Human development, happiness and control: Age, gender, occupation conditions, school level and family composition, a survey was conducted for the 333 participants in the program, same which represented at the time of the study the total population undergoing treatment and other very similar to their respective families. Both questionnaires are available for anyone interested and are not included due to document extension constraints.

Both questionnaires included 5 question modules: 1) Participant's general information, 2) Participant's socioeconomic status, 3) Program evaluation (Salas para la Paz), 4) Participant’s level of human development, and 5) Participant's level of happiness and satisfaction with life. This custom design allows counting data from one part of the variables that theoretically might have an influence on addictive behavior and on the effects of any program treating it. An aspect left for studying in the future was related to family history, which is present as an explanatory variable for addiction in practically every theoretical perspective, but demands for more extent and 
specialized studies than the present one, in which the roots of the problem are addressed in the behaviors, ideas and relationship types that prevail in the family.

The fourth module in the questionnaires includes the human development measurement tool elaborated and tested by [10], which was adapted for the present study, discarding points $3,5,17,34,46,54$, and 55, due to not having any relationship with the present analysis. This instrument evaluates 6 subscales with scores from 1 to 4 (see Table 2). Scores have equivalences to each level of each subscale, which are shown on Table 3 . The elements integrated by [10] involve a fair amount of the faces noticed by [18] as they consider the human development perspective for the treating and understanding addictions.

To evaluate the impact of the Salas para la Paz program, the propensity score matching method was used, which allows to control by differences in observable characteristics of the individuals receiving treatment. In this case, control variables were: age, gender, it the person has had a job, if he or she knows how to read, last year of studies coursed and number of family members. By adding the variable that identifies marital status, the age variable becomes unbalanced, so it was decided not to use the civil status variable as part of the control variables.

\section{Results and Discussion}

Results are presented in two sections, according to the type of survey conducted: Surveys for direct participants, and surveys for family members.

\subsection{Participants' Surveys}

The main hypothesis suggests that people increase their levels of human development and happiness as they

Table 2. Equivalences on a subscale level.

\begin{tabular}{ccc}
\hline Results range & Equivalence \\
\hline $1<\mathrm{x}<1.6$ & 1 \\
$1.6<\mathrm{x}<2.2$ & 2 \\
$2.2<\mathrm{x}<2.8$ & 3 \\
$2.8<\mathrm{x}<3.4$ & 4 \\
$3.4<\mathrm{x}<4$ & 5 \\
\hline
\end{tabular}

Source: Created by authors based on [10].

Table 3. Equivalences for the human development measurement tool.

\begin{tabular}{cc}
\hline Result range & Equivalence (Level of Human Development) \\
$6<\mathrm{x}<7.8$ & Lowest \\
$7.8<\mathrm{x}<9.6$ & Lowest and lower \\
$9.6<\mathrm{x}<11.4$ & Low level \\
$11.4<\mathrm{x}<13.2$ & Low and medium \\
$13.2<\mathrm{x}<15$ & Medium \\
$15<\mathrm{x}<16.8$ & Medium and higher \\
$16.8<\mathrm{x}<18.6$ & High level \\
$18.6<\mathrm{x}<20.4$ & High and very high \\
$20.4<\mathrm{x}<22.2$ & Very high \\
$22.2<\mathrm{x}<24$ & \\
\hline
\end{tabular}

Source: Created by authors based on [10]. 
become involved for more time in the Salas para la Paz program. Therefore, it is expected to find a statistically significant difference between the levels of human development in the control and in the treatment group.

T-tests for mean difference comparison between control and treatment groups were developed, where the null hypothesis sustains that there is no statistically significant difference between the subscales for indicating level of human development, between those who were treated for more than ten months, and those who were treated for less time. Also, tests were conducted in order to compare the self-reported happiness level by both groups.

Table 4 summarizes the T-tests results on mean differences. Normal distribution and a two tailed test were considered, with $\alpha=0.05$, from which can be derived that the acceptation range for the null hypothesis would be among -1.96 and +1.96 , or even more distanced from both sides to 0 .

For the comparison for the human development level, as well as for each of the six elements that integrate it, and the three happiness levels, differences between treatment and each of the three control groups, show that there is no statistically significant difference among them, since t calculate was always between the acceptation range for the null hypothesis. This would indicate that according to answers from direct participants in the program Salas para la Paz, there is no perception of increase of human development level, or in happiness level, after staying in the program for 10 or more months, compared to that obtained after for months or less, two months or less, or even a month or less of treatment, this last ones considered equivalent to not receiving the treatment.

Due to the fact that mean difference tests don't control the effect that other variables may cause to the program, that may affect the results of which, we proceeded to estimate the effects of treatment by using the propensity score matching methods proposed by [22], which estimation bias and allow to control other variables. The average for the treatment effect on the involved population was determined by using [23] procedure and syntax, ATTND (Average Treatment on the Treated, Nearest Neighbor). With this method the result obtained by each benefactor treated is compared with that of the control group participant who has the closest score. By doing so, the difference between each pair of associated units for the interest variable is calculated, and all of these differences are made into an average in order to calculate the ATT, whose expected value is the difference between the values of the expected result with and without treatment, for those involved in the treatment.

In a first stage, observable characteristics of individuals used as control variables were age and gender. Results match with T-tests, only subscales of coherence and satisfaction have the expected result, and there is no statistically significant evidence that demonstrates that there is a difference between each subscales scores or for the indicators on human development and happiness.

In the second stage the next variables were used as control: If the person has had a job, if he or she knows how to read, the last year of studies coursed, and number of family members. These variables were selected according to two criteria that, on one hand make sense in terms of the theoretical framework on addictions, mostly that which refers to social environment and Sen's capabilities approach, and in the other hand, because they share the ability to balance scores. Like with T-tests, no statistically significant differences were found on any of the subscales, or in the comparisons between the treatment group and the three control groups. Estimations are summarized on Table 5 and Table 6.

Table 4. Means and T-test differential means, between treatment group and the three control groups (Survey conducted on people in treatment).

\begin{tabular}{|c|c|c|c|c|c|c|c|}
\hline $\begin{array}{c}\text { Component of human } \\
\text { development }\end{array}$ & Treatment group & $\begin{array}{c}\text { Control } \\
\text { group } \leq 4 \text { months }\end{array}$ & $\mathrm{T}$ value & $\begin{array}{c}\text { Control } \\
\text { group } \leq 2 \text { months }\end{array}$ & T value & $\begin{array}{c}\text { Control } \\
\text { group } \leq 1 \text { month }\end{array}$ & $\mathrm{T}$ value \\
\hline Openness & 2.73 & 2.83 & 1.266 & 2.78 & 0.518 & 2.77 & 0.357 \\
\hline Responsibility & 2.67 & 2.77 & 1.217 & 2.68 & 0.260 & 2.70 & 0.292 \\
\hline Coherence & 2.71 & 2.70 & -0.178 & 2.74 & 0.263 & 2.73 & 0.194 \\
\hline Satisfaction & 2.53 & 2.52 & -0.161 & 2.51 & -0.185 & 2.56 & 0.358 \\
\hline Sense of security & 2.60 & 2.62 & 0.336 & 2.66 & 0.704 & 2.68 & 0.799 \\
\hline Closeness in relationships & 2.75 & 2.82 & 1.244 & 2.76 & 0.405 & 2.78 & 0.545 \\
\hline Human development & 15.77 & 16.17 & 0.903 & 15.97 & 0.377 & 16.01 & 0.377 \\
\hline Happiness & 8.06 & 7.7 & -1.171 & 7.8 & -0.732 & 7.63 & -1.021 \\
\hline
\end{tabular}

Source: Developed by authors. 
Table 5. Effect of treatment on the treated, closest neighbor. Control variables: Age and gender.

\begin{tabular}{|c|c|c|c|c|c|c|c|c|}
\hline Group and statistics & Openness & Responsibility & Coherence & Satisfaction & $\begin{array}{l}\text { Feeling of } \\
\text { Security }\end{array}$ & $\begin{array}{l}\text { Closeness in } \\
\text { relationships }\end{array}$ & $\begin{array}{l}\text { Indicator of } \\
\text { development }\end{array}$ & Happiness \\
\hline Controls $\leq 4$ months & 116 & 106 & 115 & 111 & 102 & 117 & 92 & 120 \\
\hline Treatments & 103 & 103 & 103 & 103 & 103 & 103 & 103 & 103 \\
\hline ATTND & -0.082 & -0.148 & 0.064 & 0.005 & -0.023 & -0.069 & -0.270 & 0.779 \\
\hline Standard deviation & 0.081 & 0.093 & 0.089 & 0.074 & 0.074 & 0.089 & 0.426 & 0.354 \\
\hline T value & -1.010 & -1.588 & 0.725 & 0.065 & -0.313 & -0.777 & -0.635 & 2.197 \\
\hline Controls $\leq 2$ months & 65 & 56 & 66 & 62 & 55 & 65 & 50 & 68 \\
\hline Treatments & 103 & 103 & 103 & 103 & 103 & 103 & 103 & 103 \\
\hline ATTND & -0.122 & -0.139 & -0.079 & -0.072 & -0.217 & -0.145 & -0.774 & 0.385 \\
\hline Standard deviation & 0.100 & 0.112 & 0.107 & 0.081 & 0.087 & 0.111 & 0.537 & 0.461 \\
\hline T value & -1.214 & -1.240 & -0.742 & -0.892 & -2.484 & -1.311 & -1.442 & 0.834 \\
\hline Controls $\leq 1$ month & 41 & 36 & 42 & 38 & 34 & 41 & 31 & 43 \\
\hline Treatments & 103 & 103 & 103 & 103 & 103 & 103 & 103 & 103 \\
\hline ATTND & 0.050 & -0.082 & 0.038 & -0.013 & -0.122 & -0.093 & -0.104 & 0.107 \\
\hline Standard deviation & 0.135 & 0.132 & 0.125 & 0.099 & 0.111 & 0.140 & 0.667 & 0.577 \\
\hline T value & 0.372 & -0.625 & 0.302 & -0.129 & -1.099 & -0.663 & -0.155 & 0.186 \\
\hline
\end{tabular}

Source: Developed by authors.

Table 6. Effect of treatment on the treated, closest neighbor. Control variables: age, gender, if the person has had a job, if he or she knows how to read, last year of studies coursed and number of family members.

\begin{tabular}{|c|c|c|c|c|c|c|c|c|}
\hline Group and statistics & Openness & Responsibility & Coherence & Satisfaction & $\begin{array}{c}\text { Feeling of } \\
\text { security }\end{array}$ & $\begin{array}{l}\text { Closeness in } \\
\text { relationships }\end{array}$ & $\begin{array}{l}\text { Indicator of } \\
\text { development }\end{array}$ & Happiness \\
\hline Controls $\leq 4$ months & 52 & 42 & 51 & 49 & 42 & 52 & 35 & 53 \\
\hline Treatments & 84 & 84 & 84 & 84 & 84 & 84 & 84 & 84 \\
\hline ATTND & -0.193 & -0.105 & 0.041 & -0.092 & 0.015 & -0.094 & -0.433 & 0.67 \\
\hline Standard deviation & 0.101 & 0.105 & 0.102 & 0.084 & 0.091 & 0.109 & 0.507 & 0.47 \\
\hline T value & -1.923 & -1.001 & 0.402 & -1.100 & 0.169 & -0.865 & -0.853 & 1.425 \\
\hline Controls $\leq 2$ months & 34 & 25 & 35 & 30 & 26 & 34 & 21 & 34 \\
\hline Treatments & 84 & 84 & 84 & 84 & 84 & 84 & 84 & 84 \\
\hline ATTND & -0.179 & -0.148 & -0.106 & 0.005 & -0.028 & -0.141 & -0.486 & 0.746 \\
\hline Standard deviation & 0.127 & 0.144 & 0.125 & 0.100 & 0.110 & 0.126 & 0.710 & 0.555 \\
\hline T value & -1.410 & -1.033 & -0.848 & 0.050 & -0.257 & -1.121 & -0.693 & 1.344 \\
\hline Controls $\leq 1$ month & 31 & 24 & 31 & 28 & 25 & 31 & 21 & 34 \\
\hline Treatments & 84 & 84 & 84 & 84 & 84 & 84 & 84 & 84 \\
\hline ATTND & 0.149 & 0.147 & 0.082 & 0.129 & 0.141 & 0.173 & 1.061 & 0.203 \\
\hline Standard deviation & 0.134 & 0.181 & 0.136 & 0.107 & 0.101 & 0.134 & 0.710 & 0.537 \\
\hline $\mathrm{T}$ value & 1.114 & 0.815 & 0.603 & 1.202 & 1.386 & 1.291 & 1.495 & 0.377 \\
\hline
\end{tabular}

Source: Developed by authors. 
Compared to T-tests, by using Propensity Score Matching, many of the individual elements that integrate the human development index, came across with the expected difference, in this case, negative, since the scores were higher on the participants of the program, against their best version in the control group, but, as it was mentioned before, none of these was statistically significant.

\subsection{Family Members' Surveys}

Family members represent an important part of the analysis of the effects of treatment, since they become involved in the effects of the program, and are also close witnesses of possible changes experienced by their relative undergoing treatment, who, because of its own condition, might not be completely reliable on his or her answers.

The analysis of density distribution of the scores of each subscale shows a larger difference between control and treatment group, than that observed in the results obtained from the survey conducted on the program's participants. The relatives answers of participants who have been in treatment for 10 or more months show a larger density on scores close to 4 (maximum value) in comparison to the answers of the realities of participants who have been in treatment for less than 10 months.

T-tests revealed results similar to the ones mentioned before, and again the null hypothesis states that there is no statistically significant difference between the means of the interest variables, for people who were in treatment for a period of more than 10 months and those who only were treated for equal to, or less than 4, 2 and 1 months. A remarkable fact is that the signs of the differences between the means of both groups changed practically in every indicator and now reflect the expected sign (negative), which speaks of a difference, where both the general indicator of human development, and each of the elements that compose it, were higher on the treatment group than in the control groups, but such difference was not statistically significant in practically none of the cases, considering that $\alpha=0.05$. This result didn't affect the happiness variable, where the treatment group was less happy than any of the control groups, though no difference was statistically significant in this case. It is important to mention that if $\alpha=0.10$, the number of statistically significant differences would increase, and even the general indicator of human development would be significant when comparing the treatment group with the group with one month or less in the program.

Table 7 contains the results for mean difference tests, according to the perception of the relatives or family members of the individuals undergoing treatment.

Similarly to the results obtained from the survey conducted on participants in the program, in this section, that refers to results obtained from the survey conducted on family members or relatives, the tests based on propensity score matching between the participants from the group with 10 or more months and their similar in the control groups are also reported, controlling the same variables in two stages, but first considering only age and gender, and in the second stage also considering if the person has had a job, if he or she knows how to read, last year of studies coursed and number of family members. It also tries to control by the participant's time on addiction,

Table 7. Mean and mean difference t-tests, between the treatment group and the three control groups.

\begin{tabular}{cccccccc}
\hline $\begin{array}{c}\text { Element of human } \\
\text { development }\end{array}$ & $\begin{array}{c}\text { Treatment } \\
\text { group }\end{array}$ & $\begin{array}{c}\text { Control } \\
\text { group } \leq 4 \text { months }\end{array}$ & T value & $\begin{array}{c}\text { Control } \\
\text { group } \leq 2 \text { months }\end{array}$ & T value & $\begin{array}{c}\text { Control } \\
\text { group } \leq 1 \text { month }\end{array}$ & T value \\
\hline Openness & 2.67 & 2.52 & -1.632 & 2.44 & -2.042 & 2.39 & -2.017 \\
Responsibility & 2.75 & 2.56 & -1.618 & 2.58 & -1.167 & 2.44 & -1.936 \\
Coherence & 2.60 & 2.51 & -0.812 & 2.46 & -1.138 & 2.46 & -0.927 \\
Satisfaction & 2.52 & 2.48 & -0.407 & 2.42 & -0.967 & 2.43 & -0.697 \\
$\begin{array}{c}\text { Sense of security } \\
\text { Closeness in }\end{array}$ & 2.60 & 2.47 & -1.518 & 2.41 & -1.697 & 2.43 & -1.257 \\
relationships & 2.72 & 2.54 & -1.497 & 2.46 & -1.760 & 2.32 & -2.182 \\
Human development & 15.98 & 15.17 & -1.191 & 14.63 & -1.622 & 14.32 & -1.668 \\
Happiness & 7.98 & 8.18 & 0.512 & 8.14 & 0.319 & 8.47 & 0.804 \\
\hline
\end{tabular}

Source: Developed by authors. 
but this variable didn't accomplish the balancing property, that this test requires.

The results are reported on Table 8 and Table 9. In general, the difference generated by the program is not

Table 8. Effect of treatment on the treated, closest neighbor. Control variables: age and gender.

\begin{tabular}{ccccccccc}
\hline Group and statistics & \multicolumn{2}{c}{ Openness Responsibility Coherence Satisfaction } & $\begin{array}{c}\text { Feeling of } \\
\text { security }\end{array}$ & $\begin{array}{c}\text { Closeness in } \\
\text { relationships }\end{array}$ & $\begin{array}{c}\text { Indicator of } \\
\text { development }\end{array}$ & Happiness \\
\hline Controls $\leq 4$ months & 40 & 47 & 41 & 36 & 37 & 34 & 28 & 47 \\
Treatments & 103 & 103 & 103 & 103 & 103 & 103 & 103 & 103 \\
ATTND & 0.094 & 0.067 & 0.098 & -0.069 & 0.115 & 0.119 & 0.539 & -0.180 \\
Standard deviation & 0.093 & 0.130 & 0.096 & 0.078 & 0.078 & 0.115 & 0.498 & 0.433 \\
T value & 1.007 & 0.514 & 1.028 & -0.879 & 1.475 & 1.036 & 1.082 & -0.415 \\
Controls $\leq 2$ months & 25 & 28 & 26 & 20 & 21 & 21 & 17 & 27 \\
Treatments & 103 & 103 & 103 & 103 & 103 & 103 & 103 & 103 \\
ATTND & 0.234 & 0.133 & 0.223 & 0.005 & 0.163 & 0.238 & 1.158 & 0.103 \\
Standard deviation & 0.130 & 0.174 & 0.136 & 0.102 & 0.110 & 0.144 & 0.739 & 0.533 \\
T value & 1.802 & 0.766 & 1.643 & 0.053 & 1.485 & 1.650 & 1.567 & 0.194 \\
Controls $\leq 1$ month & 16 & 18 & 16 & 11 & 12 & 12 & 9 & 17 \\
Treatments & 103 & 103 & 103 & 103 & 103 & 103 & 103 & 103 \\
ATTND & 0.318 & 0.378 & 0.171 & -0.016 & -0.122 & 0.503 & 2.083 & -0.274 \\
Standard deviation & 0.318 & 0.197 & 0.186 & 0.134 & 0.111 & 0.164 & 1.009 & 0.562 \\
T value & 2.045 & 1.918 & 0.917 & -0.118 & -1.099 & 3.068 & 2.065 & -0.488 \\
\hline
\end{tabular}

Source: Developed by authors.

Table 9. Effect of treatment on the treated, closest neighbor. Control variables: age, gender, if the person has had a job, if he or she knows how to read, last year of studies coursed and number of family members.

\begin{tabular}{|c|c|c|c|c|c|c|c|c|}
\hline Group and statistics & Openness & Responsibility & Coherence & Satisfaction & $\begin{array}{l}\text { Feeling of } \\
\text { security }\end{array}$ & $\begin{array}{l}\text { Closeness in } \\
\text { relationships }\end{array}$ & $\begin{array}{l}\text { Indicator of } \\
\text { development }\end{array}$ & Happiness \\
\hline Controls $\leq 4$ months & 23 & 28 & 25 & 20 & 21 & 21 & 16 & 29 \\
\hline Treatments & 89 & 89 & 89 & 89 & 89 & 89 & 89 & 89 \\
\hline ATTND & 0.109 & 0.176 & 0.001 & -0.023 & 0.110 & 0.133 & 0.249 & -0.374 \\
\hline Standard deviation & 0.124 & 0.158 & 0.123 & 0.113 & 0.114 & 0.147 & 0.695 & 0.441 \\
\hline T value & 0.884 & 1.111 & 0.009 & -0.207 & 0.963 & 0.906 & 0.359 & -0.848 \\
\hline Controls $\leq 2$ months & 21 & 22 & 20 & 16 & 17 & 19 & 15 & 22 \\
\hline Treatments & 89 & 89 & 89 & 89 & 89 & 89 & 89 & 89 \\
\hline ATTND & 0.259 & 0.116 & 0.090 & 0.135 & 0.230 & 0.234 & 0.618 & 0.158 \\
\hline Standard deviation & 0.149 & 0.201 & 0.184 & 0.141 & 0.142 & 0.182 & 1.059 & 0.658 \\
\hline T value & 1.736 & 0.579 & 0.491 & 0.962 & 1.618 & 1.286 & 0.583 & 0.241 \\
\hline Controls $\leq 1$ month & 12 & 13 & 10 & 7 & 8 & 9 & 6 & 12 \\
\hline Treatments & 89 & 89 & 89 & 89 & 89 & 89 & 89 & 89 \\
\hline ATTND & 0.531 & 0.368 & 0.442 & 0.384 & 0.364 & 0.496 & 2.509 & -0.279 \\
\hline Standard deviation & 0.174 & 0.245 & 0.239 & 0.114 & 0.175 & 0.197 & 1.198 & 0.780 \\
\hline T value & 3.060 & 1.502 & 1.848 & 3.378 & 2.080 & 2.516 & 2.095 & -0.358 \\
\hline
\end{tabular}

Source: Developed by authors. 
statistically significant for practically any of the variables of interest when comparing treatment group and groups with 4 and 2 months or less in treatment, but when comparing with those who are just starting, this is, the group with 1 month or less in treatment, all indicators show a statistically significant difference, that would prove the effect intended by the program, which is to raise the indicator of human development and a fair part of its components for its participants.

The present study explains the impact of the program Salas para la Paz, by Promoción de Paz, A.B.P., from the perspective of the participant, as from the perspective of its closest relatives. The results obtained allow concluding that, from the perspective of the relatives of the person undergoing treatment, the program does contribute to the growth of the person's human development. On the other hand, the effects are null if the participant's perspective is considered.

In the results obtained from surveys conducted on relatives, it is evident that the effects of the program on human development increase as the subject stays more time on treatment. Also, even though these effects are positive and statistically significant, they can be considered to be minimum, which indicates that 10 months could be insufficient to reach the objectives the program pursues.

On his approach on human development in the treatment of addictions, [18] states that there are at least 4 stages to recovery, according to his classification and based on the results of the present study, it could be said that the program, in 10 months, helps to reach an go through the second and third stages, this means that the participant is able to consider the possibility of change, is receptive to intervention and starts acting by itself to reach said change, diminishing the addiction, but not sufficiently to ensure that said addiction has been reduced enough to avoid falling back into it.

Reference [18], quoting Prochaska and DiClemente (1986), states that recovery is not lineal, but cyclic, and that it may change in periods of less than a year, and therefore it is recommended to undergo treatment 2 or 3 times in order to achieve significant recovery levels.

For further studies, the size of control groups will be increased and other control variables will be introduced, mostly those related to family history and interpersonal relationships in the family.

\section{Acknowledgements}

To José Salazar Pozos, for his help in the translation of the base document.

\section{References}

[1] Hernández, D., Orozco, M. and Vázquez, S. (2008) Métodos de focalización en la política social en México. Un estudio comparativo.economía mexicana. Nueva Época, 17, 101-137. http://www.economiamexicana.cide.edu/num anteriores/XVII-1/04 HERNANDEZ 101-137.pdf

[2] Promoción de Paz (No Year) Salas para la Paz: un espacio para prevenir la violencia, las adicciones y los delitos. Non-Published Document.

[3] Consejo Nacional de Evaluación de la Política de Desarrollo Social (2006) Evaluación de impacto del Programa de Desarrollo Humano Oportunidades. http://evaluacion.oportunidades.gob.mx:8010/es/docs/docs2006.php

[4] Consejo Nacional de Evaluación de la Política de Desarrollo Social (2008) Evaluación de impacto del Programa de Desarrollo Humano Oportunidades. http://evaluacion.oportunidades.gob.mx:8010/es/docs/docs2008.php

[5] Consejo Nacional de Evaluación de la Política de Desarrollo Social (2008) Evaluación específica de desempeño del Programa Educativo en Materia de Prevención de Adicciones. http://www.sep.gob.mx/es/sep1/sep1_Programa_Educativo_en_Materia_de_Prevencion_d

[6] Campbell, D. and Stanley, J. (2005) Diseños experimentales y cuasiexperimentales en la investigación social. Amorrortu, Buenos Aires.

[7] Langbein, L. and Felbinger, C. (2006) Public Program Evaluation. M. E. Sharpe, New York.

[8] Sen, A. (1996) Capacidad y bienestar. In: Nussbaum, M.C. and Sen, A., Eds., La calidad de vida, Fondo de Cultura Económica, México, 54-83.

[9] Sen, A. (2010) La idea de la justicia. Taurus, México.

[10] Ruiz, M. (2004) Elaboración de un instrumento de medición del desarrollo humano para estudiantes de ingeniería. Ph.D. Thesis, Universidad Iberoamericana, México DF.

[11] West, R. (2001) Theories of Addiction. Addiction, 96, 3-13. http://onlinelibrary.wiley.com/doi/10.1046/j.1360-0443.2001.96131.x/epdf 
http://dx.doi.org/10.1046/j.1360-0443.2001.96131.x

[12] Bobo Kovac, V. (2013) The More the 'Merrier': A Multi-Sourced Model of Addiction. Addiction Research \& Theory, 21, 19-32. http://informahealthcare.com/doi/pdfplus/10.3109/16066359.2012.691581 http://dx.doi.org/10.3109/16066359.2012.691581

[13] Drummond, D.C. (2001) Theories of Drug Craving, Ancient and Modern. Addiction, 96, 33-46. http://onlinelibrary.wiley.com/doi/10.1046/j.1360-0443.2001.961333.x/epdf http://dx.doi.org/10.1046/j.1360-0443.2001.961333.x

[14] Graham, M.D., Young, R.A., Valach, L. and Wood, R. (2008) Addiction as a Complex Social Process: An Action Theoretical Perspective. Addiction Research and Theory, 16, 121-133.

http://informahealthcare.com/doi/pdfplus/10.1080/16066350701794543 http://dx.doi.org/10.1080/16066350701794543

[15] Becker, G.S. and Murphy, K.M. (1988) A Theory of Rational Addiction. Journal of Political Economy, 96, 675-700. http://www.jstor.org/stable/1830469?seq=1\&cid=pdf-reference\#references tab contents http://dx.doi.org/10.1086/261558

[16] Brown, L.G. (1931) The Sociological Implications of Drug Addictions. Journal of Educational Sociology, 4, 358-369. http://www.jstor.org/stable/2961617 http://dx.doi.org/10.2307/2961617

[17] Alter, A. (2013) Where We Are Shapes Who We Are. The New York Times, SR 12. http://www.nytimes.com/2013/06/16/opinion/sunday/a-self-defined-by-place.html

[18] Wallen, J. (1993) Addiction in Human Development: Developmental Perspectives on Addiction and Recovery. The Haworth Press, New York.

[19] Stigler, G. and Becker, G. (1977) De Gustibus Non Est Disputandum. The American Economic Review, 67, 76-90. http://www.jstor.org/stable/1807222

[20] Pacula, R. (1997) Economic Modelling of the Gateway Effect. Health Economics, 6, 521-524. http://onlinelibrary.wiley.com/doi/10.1002/(SICI)1099-1050(199709)6:5\%3C521::AID-HEC301\%3E3.0.CO;2-6/epdf http://dx.doi.org/10.1002/(SICI)1099-1050(199709)6:5<521::AID-HEC301>3.0.CO;2-6

[21] Johnson, P. and Glassman, M. (1998) The Relationship between Ethnicity, Gender and Alcohol Consumption: A Strategy for Testing Competing Models. Addiction, 93, 583-588. http://onlinelibrary.wiley.com/doi/10.1046/j.1360-0443.1998.93458313.x/epdf http://dx.doi.org/10.1046/j.1360-0443.1998.93458313.x

[22] Rosenbaum, P. and Rubin, D. (1983) The Central Role of Propensity Score Matching in Observational Studies for Causal Effects. Biometrika, 70, 41-55. http://biomet.oxfordjournals.org/content/70/1/41.full.pdf+html http://dx.doi.org/10.1093/biomet/70.1.41

[23] Becker, S.O. and Ichino, A. (2002) Estimation of Average Treatment Effects Based on Propensity Scores. The Stata Journal, 4, 358-377. http://www.stata-journal.com/article.html?article=st0026 